\title{
Social differentiation and well-being in the Italian Iron Age: exploring the relationship between sex, age, biological stress, and burial complexity among the Picenes of Novilara (8th-7th c. BC)
}

\author{
Zita Laffranchi ${ }^{1,2,3}$ (D) Michael A. Beck De Lotto ${ }^{4}$ (D) $\cdot$ C. Delpino ${ }^{5} \cdot$ Sandra Lösch $^{1}$ (D) $\cdot$ Marco Milella $^{1}$ (D)
}

Received: 18 March 2021 / Accepted: 13 September 2021 / Published online: 7 October 2021

(c) The Author(s) 2021

\begin{abstract}
The possible association between "biological" and "social" status in the past is a central topic in bioarchaeological studies. For the Italian Iron Age, previous research comparing skeletal and funerary variables depicts a multifaceted scenario consistent with nuanced biocultural patterns. This calls for additional studies on a broader series of archaeological contexts and skeletal assemblages. Here, we contribute new data about the biological correlates of social differentiation during the Italian Iron Age by comparing paleopathological and funerary variables in the Picene necropolis of Novilara (Marche region, 8th-7th c. BC). Novilara is one of the largest Picene necropolises in the Italian Peninsula and one of the most important funerary sites of the Italian Iron Age. The skeletal sample includes 147 individuals (females: 70; males: 35; 10 unsexed adults; 32 non-adults). We use linear enamel hypoplasia, cribra orbitalia, porotic hyperostosis, non-specific periosteal lesions, and stature to approximate non-specific stressors and compare them with archaeological variables summarizing funerary variability by means of logistic models, Mann-Whitney and Spearman tests. Results are heterogeneous and vary according to the considered variables. On average, they however show that (a) adults featuring a more complex funerary treatment have a lower probability of showing stress-related skeletal changes, and (b) even though funerary features suggests a strong gender differentiation, frequencies of paleopathological variables do not differ between sexes. Our analyses point to a complex link between biological and social status in this population and call for a critical reflection about the theoretical and methodological issues affecting similar studies.
\end{abstract}

Keywords Non-specific stress markers $\cdot$ Funerary treatment $\cdot$ Stature $\cdot$ Iron Age $\cdot$ Picene culture

\section{Introduction}

Marco Milella

marco.milella@irm.unibe.ch

1 Department of Physical Anthropology, Institute of Forensic Medicine, IRM- University of Bern, Bern, Switzerland

2 Department of Prehistory and Archaeology, Faculty of Letters and Philosophy, University of Granada, Granada, Spain

3 Department of Legal Medicine, Toxicology and Physical Anthropology, Faculty of Medicine, University of Granada, Granada, Spain

4 Department of Cultural Heritage: Archaeology, History of Art, Cinema and Music, Faculty of Letters and Philosophy, University of Padova, Padova, Italy

5 Superintendence of Archaeology, Fine Arts and Landscape for the Provinces of Frosinone and Latina-Ministry of Culture, L'Aquila, Italy
The potential association between status, wealth, and health patterns (Marmot and Bell 2016; Nguyen and Peschard 2003; Pechenkina and Delgado 2006; Rathbun and Steckel 2003) informs a long tradition of bioarchaeological studies focused on the exploration of links between "social and biological status" (sensu Robb et al. 2001). Bioarchaeological proxies of social status may include various types of funerary features (e.g., type and amount of grave goods). Dental, skeletal, and stable isotope data are usually used as proxies of biological status: exposure to environmental and biomechanical stress and relative access to food resources (e.g., Laffranchi et al. 2019; Minozzi et al. 2020; Reitsema and Vercellotti 2012; Robb et al. 2001; Sparacello et al. 2015, 2017; Vercellotti et al. 2011; Weiss et al. 2019).

Bioarchaeological comparisons of social and biological status are often complicated by a number of theoretical 
and methodological issues. Especially when lacking written sources, classifications of burials into "elite" or "nonelite" risk to be affected by subjective bias (Härke 2000; Pechenkina and Delgado 2006; Robb et al. 2001). Furthermore, social status is rarely a fixed variable and not necessarily just a representation of personal wealth. Another issue relates to the social and biological representation of the analyzed skeletal sample. A necropolis may reflect the self-representation of a community rather than its objective mirror image (Cuozzo 1996, 2000; D'Agostino 1985; Parker Pearson 1982, 1993). This may concretize in selective burial practices and/or the allocation of burial areas to specific members/segments of a society. This, in turn, would result in a bias of the social and demographic composition of the analyzed population (e.g., apparent absence of rich burials, underrepresentation of infants) leading to fundamental interpretive challenges.

From a biological point of view, the main issues include the type of information provided by skeletal and dental data and the challenges posed by the "osteological paradox" (Wood et al. 1992). Skeletal and dental data can provide only a fragmentary perspective on past "health" (Temple and Goodman 2014). The latter, in its medical meaning, incorporates indeed a number of archaeologically invisible variables (see WHO 1948). In addition, the anthropological variables typically used as proxy of biological status (e.g., cribra orbitalia, enamel hypoplasia) have a complex etiology, which limits their applicability beyond the exploration of general stress patterns. Heterogeneity in disease risk, selective mortality, and demographic non-stationarity adds to these issues (Wood et al. 1992). Different publications have addressed these problems, leading to new or revised theoretical and methodological approaches (e.g., Laffranchi et al. 2019; McFadden and Oxenham 2020; Pechenkina and Delgado 2006; Sparacello et al. 2015). The recognition of the multifaceted nature of social status and health, in particular, has suggested the suitability of a nuanced approach to these studies (Robb 1997) and the suitability of multivariate methods for testing biocultural hypotheses (Laffranchi et al. 2019; Pechenkina and Delgado 2006; Sorrentino et al. 2018). In any case, considering all the above issues, the heterogeneous conclusions reached by previous comparisons of social and biological status are hardly surprising. For the Italian Peninsula (focus of this contribution), this is highlighted by a number of studies which have shown a variable correlation between archaeological and anthropological data (Laffranchi et al. 2019; Minozzi et al. 2020; Sorrentino et al. 2018; Sparacello et al. 2017; Vercellotti et al. 2011; Weiss et al. 2019).

\section{The Italian Iron Age and the Picenes: archaeological and biocultural context}

During the Early Iron Age (10th-8th c. BC) the Italian peninsula was characterized by a mosaic of populations featuring specific cultural traits and geographical distributions. In the central regions (focus of this contribution), these groups included, among others, Etruscans, Latins, Sabines, Volsci and Hernici (Latium region), Etruscans and Umbrians (Umbria), and Picenes (Marche). Similarities in material culture and other archaeological features suggest the presence of substantial networks between these communities and their cultural openness to exogenous influences (Bietti Sestieri 1992).

The Picene culture developed from the ninth century $\mathrm{BC}$ to the beginning of the third century $\mathrm{BC}$, until its incorporation in the Roman cultural sphere. The "Picenes" were distributed along the Adriatic coast, in the area limited to the west by the Apennine range and to the north and south by the rivers Foglia and Tronto, respectively. This area, ecologically diverse (from mountains to hills and plains), provides rich agricultural plains, forestry resources, and pastures. The term "Picenes" derives from Greek and Roman authors who referred to the inhabitants of this region in later periods. It is therefore prone to the same cultural and ethnic over-simplifications characterizing other similar terminologies (e.g., "Celts"). Nonetheless, independently from the specific terminology used, the Picenes have left archaeological traces (material culture and funerary customs) pointing to a strong cultural homogeneity, albeit with some degree of local cultural heterogeneity. The latter was probably favored by (a) the diverse ecology of the Marche region, (b) the presence of different networks with other cultural groups, and (c) the lack of well-defined urban centers. Most information about the Picenes comes from excavations of funerary contexts (Naso 2000; Silvestrini and Sabbatini 2008; Various authors 1992). Based on data from necropolises, the Picene culture is chronologically subdivided into six phases, from Piceno I (900-800 BC) to Piceno VI (385-268 BC) (Lollini 1976). The period between the second and third of these phases (ca. 8th-7th c. BC) is of particular interest due to an increase in the density of burials in the necropolises and the presence of selected burials with numerous and rich funerary items, which in some cases included exotic elements. This pattern hints at the rise of a social elite starting from ca. the $8^{\text {th }} \mathrm{c} \mathrm{BC}$ with a probably inherited status as suggested by infant burials with rich grave goods.

Few anthropological data are available for the Picenes, and no information is available about the possible link between social differentiation, health, and living 

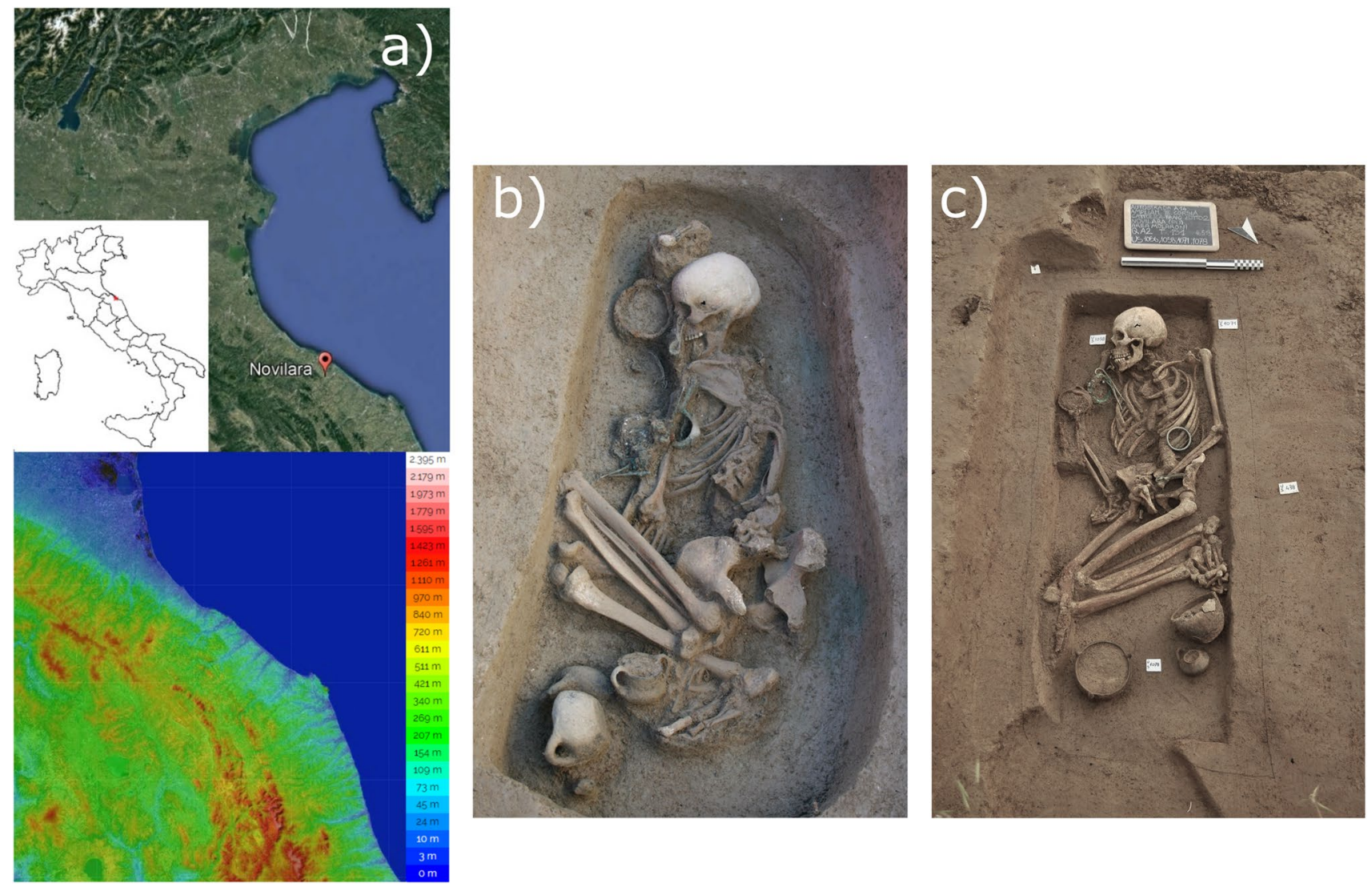

Fig. 1 Geographical position of Novilara and examples of adult burials: (a) map of Italy with localization of Novilara (above) and terrain map of the surrounding areas (below); (b-c) burials 171 (middle

conditions in this population. The present study focuses on one of the largest and best-documented Picene funerary contexts (the necropolis of Novilara) and explores the possible links between social and biological status in a Picene population. We compare demographic and funerary patterns with a suite of skeletal and dental variables (linear enamel hypoplasia, cribra orbitalia, porotic hyperostosis, non-specific periosteal lesions, and stature) potentially informative about individual exposure to physiological stress.

\section{The necropolis of Novilara}

The necropolis of Novilara (province of Pesaro and Urbino, $43^{\circ} 51^{\prime} 46.75^{\prime \prime} \mathrm{N}, 12^{\circ} 55^{\prime} 51.771^{\prime \prime} \mathrm{E}^{1}$ ), placed near the Adriatic coast in the Marche region (Fig. 1a), is one of the largest and best documented Picene funerary contexts (Baldelli 1982; Brizio 1895). First excavations during the nineteenth century led to the discovery of at least 263 burials, overall

\footnotetext{
${ }^{1}$ Geographic coordinates of the site.
}

adult female) and 151 (young adult male). Burial images courtesy of SABAP - Soprintendenza Archeologia Belle Arti e Paesaggio delle Marche

dating to ca. the 8th-seventh centuries BC (Beinhauer 1985; Brizio 1895) and distributed along two funerary areas, the Servici and Molaroni areas. The latter has been the focus of more recent investigations between 2012 and 2013. Hereby, an additional 150 burials were discovered, and 36 previously detected interments were re-excavated. All these findings also date to the 8th-seventh centuries BC.

With the exception of three incinerations, burials at Novilara conform to the funerary rituals of other Picene contexts, and include primary inhumations in simple pits, with the skeleton lying flexed or hyperflexed on their side (Delpino et al. 2016) (Fig. 1b and c). A limited number of burials at Novilara are spatially close to each other while relatively separated from the rest of the necropolis. Although the possible meaning of this "funerary cluster" is still unclear, a possible association to social differences based on status and/or kinship affiliation has been postulated (Delpino 2018; Delpino et al. 2016).

Burials includes a variable amount and type of items including vessels, weapons, pins, necklaces, and amber earrings, as well as tools related to weaving and spinning (e.g., spools, spindle whorls, spindles). Specific funerary features 
(e.g., layers of sea pebbles on the bottom and top of the pit, exotic grave goods) hint at the presence of distinct social groups in this community and to a social differentiation possibly based on status and/or geographic origin (Delpino 2018). In some cases, elaborate grave goods characterize closely spaced burials of non-adults and adults, a possible expression of social status based on kinship relationships. The level of elaboration of sporadically found garments (represented by decorations of amber, colored glass paste, and bone beads) hints at their possible ceremonial use and is of special interest.

Previous anthropological analyses of skeletal material from Novilara recovered during the nineteenth century include analyses of cranial morphology (Sergi 1907), skeletal traumas (Brasili et al. 2004), and non-masticatory dental lesions (Consiglio 2008). More recently, a series of studies have analyzed the burials exposed during the 2012-2013 campaign. Delpino (2018) provides a discussion of funerary and demographic patterns among the non-adult population. A paleogenetic study (Serventi et al. 2018) explores patterns of kinship and genetic affinity. Beck de Lotto et al. (2018) analyze patterns of trauma and interpersonal violence.

\section{Skeletal and dental markers of physiological stress}

Due to their partial correlation with environmental factors, a number of dental and skeletal features have traditionally been the focus of studies aimed at reconstructing patterns of developmental stress, health, and general living conditions among past societies. Among these variables, linear enamel hypoplasia, cribra orbitalia, porotic hyperostosis, periostitis, and stature are classically analyzed (e.g. Goodman and Rose 1990, 1991; Laffranchi et al. 2019; Larsen 2015; Rathbun and Steckel 2003; Robb 2019; Robb et al. 2001; Smith-Guzman 2015; Smith et al. 2016; Sparacello et al. 2017; Steckel et al. 2002; Vercellotti et al. 2011).

Linear enamel hypoplasia are band-like defects on the tooth crown caused by temporary disruptions of ameloblastic activity (Goodman and Rose 1990, 1991) following non-specific stress episodes during early life (Goodman and Rose 1991; Pindborg 1970, 1982; Sarnat and Schour 1941; Suckling and Thurley 1984).

Cribra orbitalia and porotic hyperostosis are porous lesions, respectively, on the roof of the orbit and on the cranial vault. They result from marrow hyperplasia, thickening of the orbital roof and diploe, and thinning of the outer cranial table during childhood. Much debate surrounds the relationship between these conditions and their link to specific etiological factors. Possible causes include various forms of anemia, parasitic infections, and chronic illness (Brickley 2018; Hengen 1971; O'Donnell et al. 2020; Stuart-Macadam and Kent 1992; Walker et al. 2009).
Periostitis is a non-specific inflammation of the periosteal surface of the bone, variously associated with infective processes (e.g., leprosy, tuberculosis, treponemal disease, fluorosis), traumas, nutritional deficiencies, and non-specific stress-related inflammatory processes (Ortner 2003). Macroscopically it can appear as accentuated longitudinal striations, osseous plaques with demarcated margins, or as irregular elevations of bone surfaces (Larsen 2015; Steckel et al. 2006). The term periostitis has recently been criticized due to its link to inflammatory states of infective origin (see Klaus 2017; Roberts 2019). Following Roberts (2019), we opted for the more generic term "nonspecific periosteal lesions".

Adult stature is determined by both genetic and environmental factors (e.g., diet and overall health) (King and Ulijaszek 1999; Maat 2005; Shin et al. 2012; Silventoinen et al. 2012; Vercellotti et al. 2011). Intrapopulation variability in stature can therefore provide useful information about differential exposure to developmental stressors possibly associated to socioeconomic changes and/or social differentiation (Cohen and Armelagos 1984; Cohen and Crane-Kramer 2007; Larsen 2006; Mieklejohn and Babb 2011; Mummert et al. 2011; Robb et al. 2001).

This study tries to address three main research questions:

a) Are there any age and/or sex patterns in funerary variability at Novilara, and what do they tell about possible social differentiation according to gender and life course stages?

b) Are there any demographic patterns in non-specific stress markers (LEH, CO, PH, NPL, stature) in this population, and what do they reveal about sex- and agerelated differences in health, with special reference to exposure to stressors during growth?

c) Is there any association in individuals who survived into adulthood between their funerary treatment and their relative exposure to health insults during growth, and what does it say about possible links between social and biological status?

\section{Material and methods}

\section{The skeletal sample}

The most recently excavated skeletal remains from Novilara amount to a minimum number of 207 individuals, corresponding to 186 burials. After excluding 60 individuals due to their extreme fragmentation, our final dataset includes 147 individuals. We determined sex only in adults ( $>20$ years old) based on the dimorphic features of the Os pubis (Phenice 1969) and of the greater sciatic notch on the ileum (Acsádi and Nemeskéri 1970; Walker 


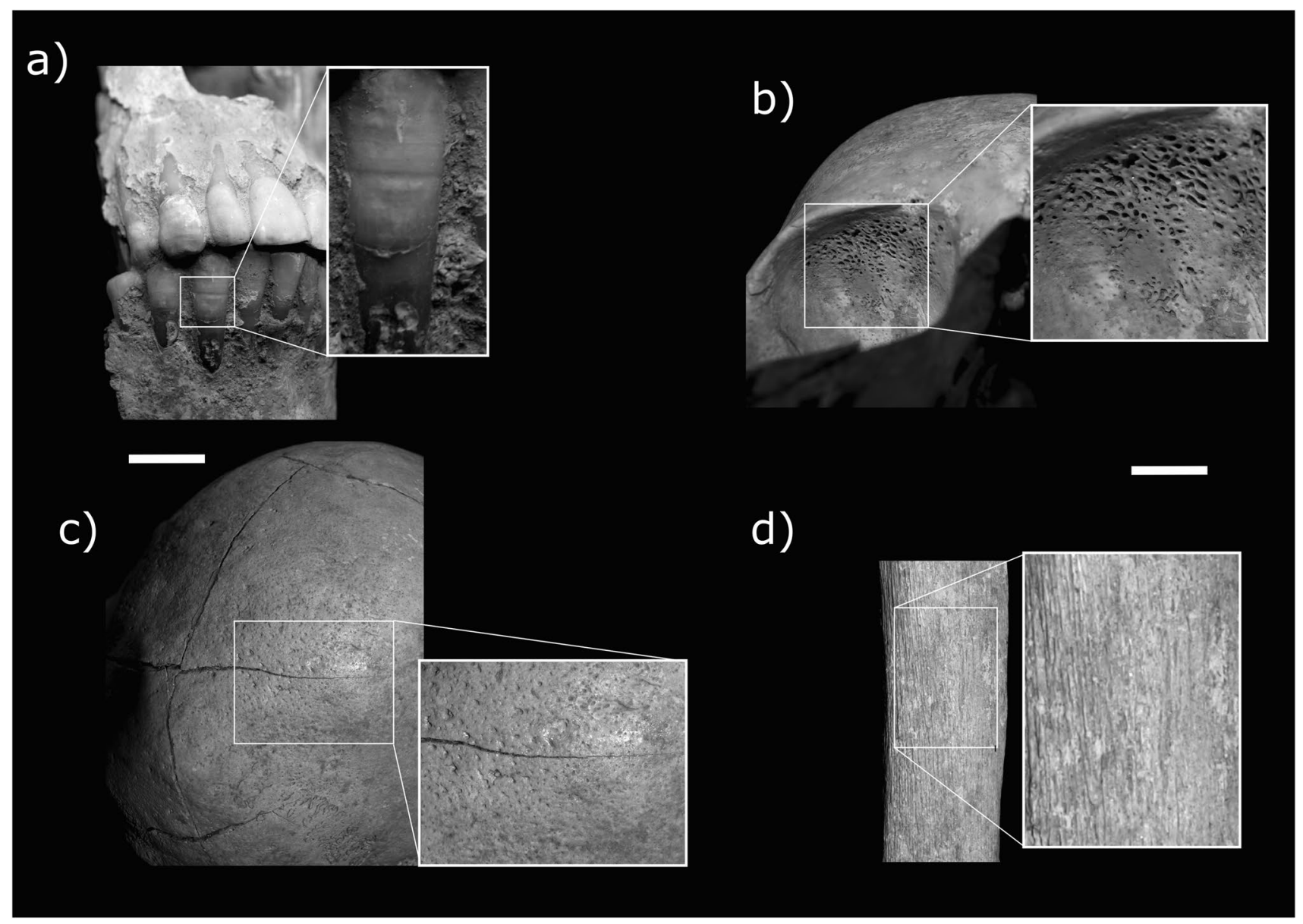

Fig. 2 Examples of the paleopathological variables in different individuals from Novilara: (a) linear enamel hypoplasia; (b) cribra orbitalia; (c) porotic hyperostosis; (d) non-specific periosteal reaction. $B$ ars $=2 \mathrm{~cm}$

2005). In a minority of cases where these elements were missing, we assessed the sexually dimorphic features of the cranium and mandible (Acsádi and Nemeskéri 1970; Ferembach et al. 1980).

We estimated adult age-at-death based on morphological changes of the pubic symphysis (Brooks and Suchey 1990; Todd 1921), the auricular surface of the ilium (Lovejoy et al. 1985), and the sternal end of the 4th rib (Işcan et al. 1984, 1985). For the estimation of non-adults' age-at-death, we used the development and eruption of the deciduous and permanent dentition (Ubelaker 1989), diaphyseal measurements, and degrees of epiphyseal fusion (Schaefer et al. 2009; Scheuer and Black 2000; Ubelaker 1989).

We then grouped individuals in six age classes following Buikstra and Ubelaker (1994): infants (I: birth to 3 years old); children $(\mathrm{C}:>3$ years to 12 years old); adolescents (Ao: $>12$ years to 20 years old); young adults (YA: $>20$ years to 35 years old); middle adults (MA: $>35$ years to 50 years old); and old adults (OA: $>50$ years old).

\section{Paleopathological variables and stature}

For each individual, we evaluated the presence of cribra orbitalia (CO, Fig. 2a), porotic hyperostosis (PH, Fig. 2c), linear enamel hypoplasia (LEH, Fig. 2b), and non-specific periosteal lesions (NPL, Fig. 2d). We then calculated, when possible, their stature.

We scored LEH on the permanent upper and lower incisors and canines with the aid of a magnifying glass following the criteria of Steckel et al. (2006). We included only teeth preserving ca. $70 \%$ of the crown and lacking extensive calculus deposits or occlusal wear (i.e., maximum wear stage of 6 according to Smith 1984). We counted LEH on an individual level, including only cases where it was possible to score at least 3 anterior teeth of different dental typologies (I1, I2, C independently of side and location) (see also Manzi et al. 1999; Minozzi et al. 2020). We then classified individuals as having LEH if they presented linear enamel defects on at least one tooth. We complemented the LEH dataset by recording the age at onset of hypoplastic defects. For this purpose, we first 
measured the distance between the first hypoplastic band and the cemento-enamel junction the nearest $0.01 \mathrm{~mm}$ with a digital caliper. With these measurements, we calculated the age at onset of LEH using the regression formula of Goodman and Rose (1990) and then grouped the estimates into 1-year classes.

We scored $\mathrm{CO}$ and $\mathrm{PH}$ macroscopically following the protocol of Steckel et al. (2006). Both variables were scored as dichotomous (presence/absence), with presence corresponding to the scores 2 and 3 of Steckel (2006). We considered only individuals with at least one preserved orbital roof (for $\mathrm{CO}$ ) and at least one parietal bone (for $\mathrm{PH}$ ).

We scored non-specific periosteal lesions (NPL) on the tibiae following Steckel et al. (2006). NPL was recorded as a dichotomous variable, with the presence of the condition corresponding to the scores 2 and 3 on at least one tibia. The dataset of NPL includes only individuals with at least $50 \%$ of one tibia preserved and without traumatic lesions on these bones (Slaus 2008).

We estimated stature applying the equations of Pearson (1899) to the length of the femur, or, if the latter was not available, of the tibia, humerus, or radius. The choice to use these formula was suggested by the results of analyses on another Iron Age population from Southern Italy (Sparacello et al. 2017) which indicated a good agreement among estimates based on different bones.

\section{Funerary classification}

In trying to summarize the funerary variability at Novilara, we opted for five dichotomous variables, describing the presence or absence of (1) grave goods, (2) weapons among grave goods, (3) textile production items among grave good, (4) elaborate garment, and (5) location of burial in a funerary cluster.

We then counted the number of grave good items in each burial and subdivided the latter into four classes: 1 ( 0 items), 2 (1-3 items), 3 (4-11 items), and 4 ( $\geq 12$ items). It is important to stress that such classification does not imply any a priori qualitative differences between numerosity classes. We are aware that the number of objects in a grave may well be linked to other factors besides status. However, since differences between numbers of items in burials do exist, we thought worthwhile to at least explore the possible association between this aspect of funerary variability and age, sex, and expression of the chosen biological features and to then discuss the possible meaning of the observed associations based on the results of the analyses. The number of classes and range of items in each class derive from the need to adequately describe the variability in grave good numerosity obtaining at the same time classes with an adequate sample size.

\section{Data analysis}

The analysis of the data included the following steps:

1) A first screening for associations between demographic, funerary, and paleopathological variables. This was performed by means of a multiple correspondence analysis (MCA). We excluded the variables number of items and age at onset of $L E H$ from the analysis in order to maximize the clarity of the results (note that the presence/absence of LEH and grave goods is in any case included). We also did not consider stature since MCA accepts only categorical variables.

This step aimed at having a broad stroke picture of the relationship between the considered variables. This, in turn, was then used to inform the following, more detailed, analyses.

2) The test for demographic patterns among paleopathological variables, stature, and funerary variables. We applied logistic models to test the association between sex and age (independent variables) and the binary paleopathological and funerary variables (for the variable number of items we used ordered logistic models). We then used a Mann-Whitney test to check for difference in stature between males and females (i.e., only adults). We applied a Spearman test to explore the correlation between age class and age at onset of LEH.

3) The test for association between paleopathological variables, stature, and funerary variables. First, we used logistic models with LEH, CO, PH, and NPL as predictors, and each funerary variable as outcome. We then tested the association between stature and funerary variables for each sex separately using Mann-Whitney tests, and when considering number of items, we applied Spearman tests.

We performed the MCA with the package FactomineR (Lê et al. 2008) for R (v. 4.0.4) (R Core Team 2021). For all the other analyses, we used JMP 15.2.0 (SAS Institute 2019), setting alpha $=0.05$.

\section{Results}

Table 1 summarizes the distribution of the analyzed skeletal sample by age class and sex. Adults and non-adult individuals represent $71.4 \%(n: 105)$ and $28.6 \%(n: 42)$ of the sample, respectively. Among sexed adults, females are twice as numerous as males ( $n$ females: $70,66.7 \%$; $n$ males: 35 , $33.3 \%$ ). Non-adults age classes present similar frequencies. Females and males show the highest frequencies for the middle adult and young adult classes, respectively. 
Table 1 Age and sex distribution of the skeletal sample. I infant; $C$ child; $A o$ adolescent; $Y A$ young adult; $M A$ middle old adult; $O A$ old adult; $A$ adult; $F$ female; $M$ male; $N A$ not assessable

\begin{tabular}{|c|c|c|c|c|c|c|c|}
\hline \multirow[t]{2}{*}{ Age class (year range) } & \multicolumn{2}{|l|}{$\mathrm{F}$} & \multicolumn{2}{|l|}{$\mathrm{M}$} & \multicolumn{2}{|c|}{$\mathrm{NA}$} & \multirow[b]{2}{*}{ Total $(\%)$} \\
\hline & $n$ & $\%$ & $n$ & $\%$ & $\mathrm{n}$ & $\%$ & \\
\hline I (0-3 y) & 0 & 0.0 & 0 & 0.0 & 10 & 23.8 & $10(6.8)$ \\
\hline$C(>3-12 y)$ & 0 & 0.0 & 0 & 0.0 & 11 & 26.2 & $11(7.5)$ \\
\hline Ao $(>12-20$ y) & 0 & 0.0 & 0 & 0.0 & 11 & 26.2 & $11(7.5)$ \\
\hline YA $(>20-35$ y) & 26 & 37.1 & 20 & 57.1 & 5 & 11.9 & $51(34.7)$ \\
\hline MA (> 35-50 y) & 31 & 44.3 & 13 & 37.1 & 3 & 7.1 & $47(32.0)$ \\
\hline $\mathrm{OA}(>50 \mathrm{y})$ & 13 & 18.6 & 2 & 5.7 & 1 & 2.4 & $16(10.9)$ \\
\hline $\mathrm{A}(>20 \mathrm{y})$ & 0 & 0.0 & 0 & 0.0 & 1 & 2.4 & $1(0.7)$ \\
\hline Total & 70 & & 35 & & 42 & & 147 \\
\hline
\end{tabular}

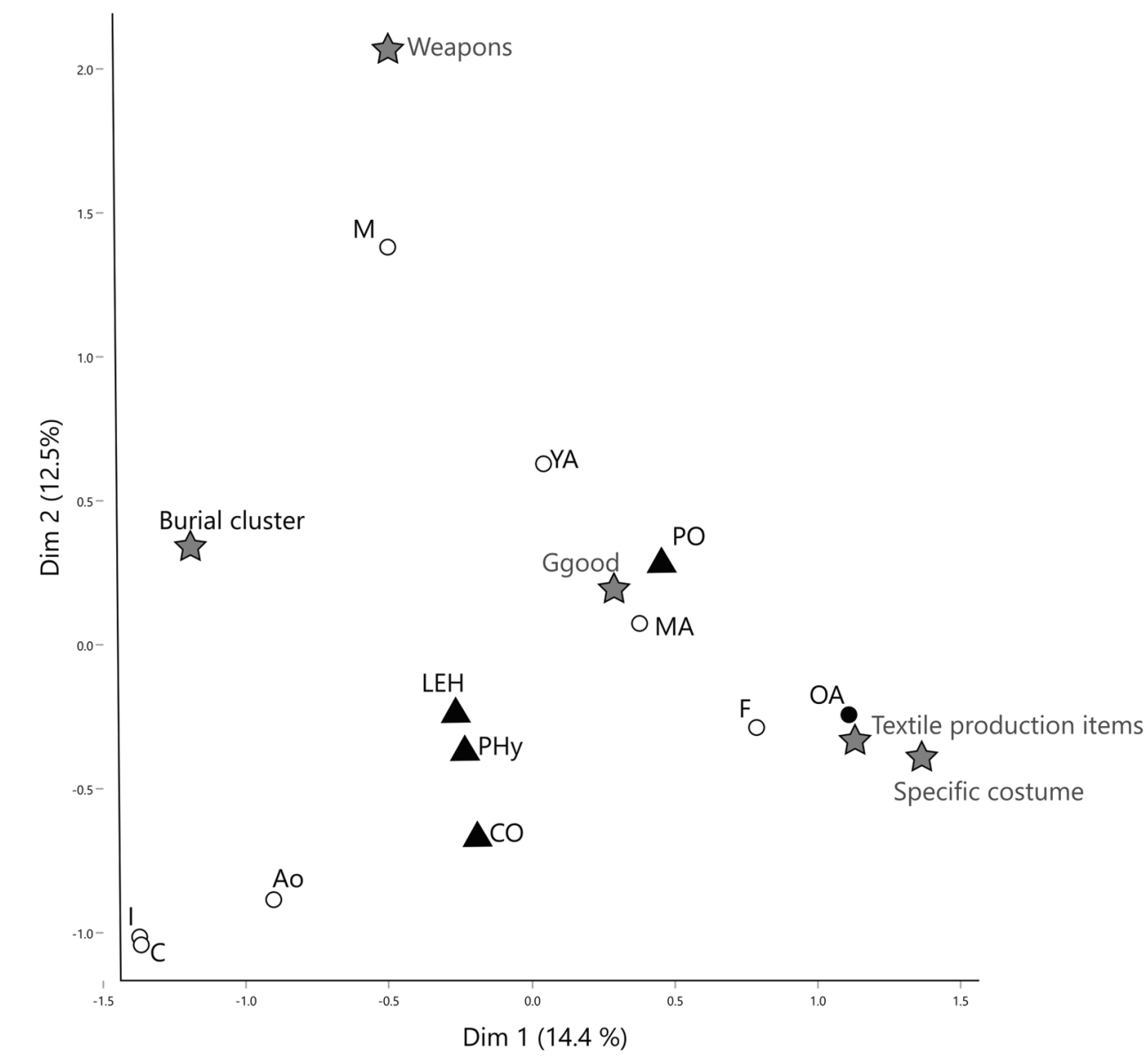

Fig. 3 Distribution of demographic, biological, and funerary variables along the first two dimensions from the MCA analysis. Circles, triangles, and stars indicate demographic, paleopathological, and funerary variables respectively. Absence of features is not shown to make the plot easier to read. M: sex corresponding to male; $\mathrm{F}$ : sex corresponding to female; I: infants; C: children; Ao: adolescents; YA: young adults; MA: middle adults; OA: old adults; Cgood: presence of grave goods.; LEH: presence of linear enamel hypoplasia; $\mathrm{CO}$ : presence of cribra orbitalia; $\mathrm{PH}$ : presence of porotic hyperostosis; NPL: presence of non-specific periosteal lesions; Ggood: presence of grave goods

\section{MCA: association between demographic, funerary, and paleopathological variables}

Figure 3 plots the first two dimensions obtained from the MCA. In order to make the plots less confusing, we show only the presence of each funerary and paleopathological variable (but the analysis included the entire dataset).

This plot provides some preliminary insights about the association between variables. Non-adult age classes are not associated with the presence of grave goods, while specific funerary features differ in their association with sex. Textile production items and elaborate garments are associated with females (especially old adult individuals), whereas weapons are associated with males.

The position of paleopathological features in each plot suggests two trends: first, the presence of LEH, PH, and $\mathrm{CO}$ is closely positioned, suggesting an association between these variables. Second, they are close to nonadult age classes, and apparently associated with the absence, in general, of grave good items and of specific grave good features. 


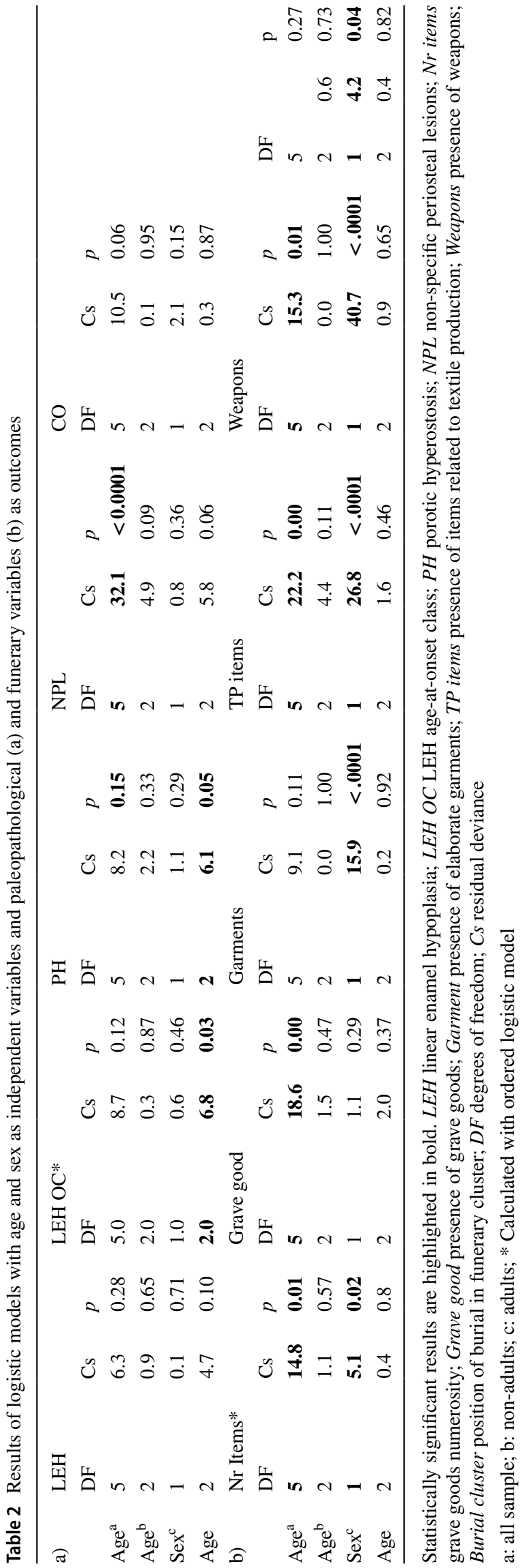

\section{Age and sex vs. paleopathological variables}

Table 2 shows the summary of the logistic models performed for the paleopathological (a ) and funerary (b ) variables. Analyses are repeated on all individuals and separately on non-adults and adults.

The analysis of all individuals highlights a statistically significant effect of age on the presence of NPL, a marginally non-significant effect on $\mathrm{CO}$, and no effect on PH, LEH, and stature.

When adults and non-adults are analyzed separately, no statistically significant association links age and paleopathological features in non-adults. Conversely, age shows in adults a significant association with PH, LEH onset class, and a marginally non-significant effect on NPL.

Sex in adults is associated with stature, as demonstrated by the Mann-Whitney test, which highlights that males are significantly taller than females (Table 3 ).

The details of the logistic models (Table S1) and ageclass-specific frequencies (Table S2a) provide information about the directions of these patterns. Incidence of $\mathrm{CO}$ shows a drop in frequencies following adolescence. LEH presents a marked increase in adolescents when compared with all the other age classes. Frequency of NPL sharply increases starting from young adults and reaches the highest frequency among old adults.

Table S3a shows the frequency of LEH age-at-onset classes for each sex and age class. As highlighted by the logistic models (Table 2), age at onset of LEH does not differ between sexes, but shows some interesting association with age-at-death. In the complete sample and in females, age at onset of LEH is concentrated around 3-4 years, whereas in males, the most represented age-at-onset classes are those between 2 and 3 and between 4 and 5 years. Spearman tests highlight a significant positive correlation between ageat-onset and age-at-death (i.e., individuals with later age at onset of LEH tend to have survived longer) in the full sample (rho: $0.3 ; p: 0.04$ ), and, especially, in females (rho: $0.7, p$ : 0.003) (Table S3b; Fig. 4). This pattern is not confirmed in adult males although this is likely to be attributed to sampling biases (the old adult male class includes only one individual).

\section{Age and sex vs. funerary treatment}

Age shows a marked influence on funerary treatment. Nonadults are in general characterized by lower frequencies of each funerary variable (Tables 2, S1, and S2b), and this is especially evident for the most "genderized" (see below) variables (e.g., elaborate garments, weapons, textile production items), which start to appear only after adolescence (Table S1). In both adults and non-adults separately, age is not associated with the presence of funerary variables. 
Archaeol Anthropol Sci (2021) 13: 182

Page 9 of $19 \quad 182$

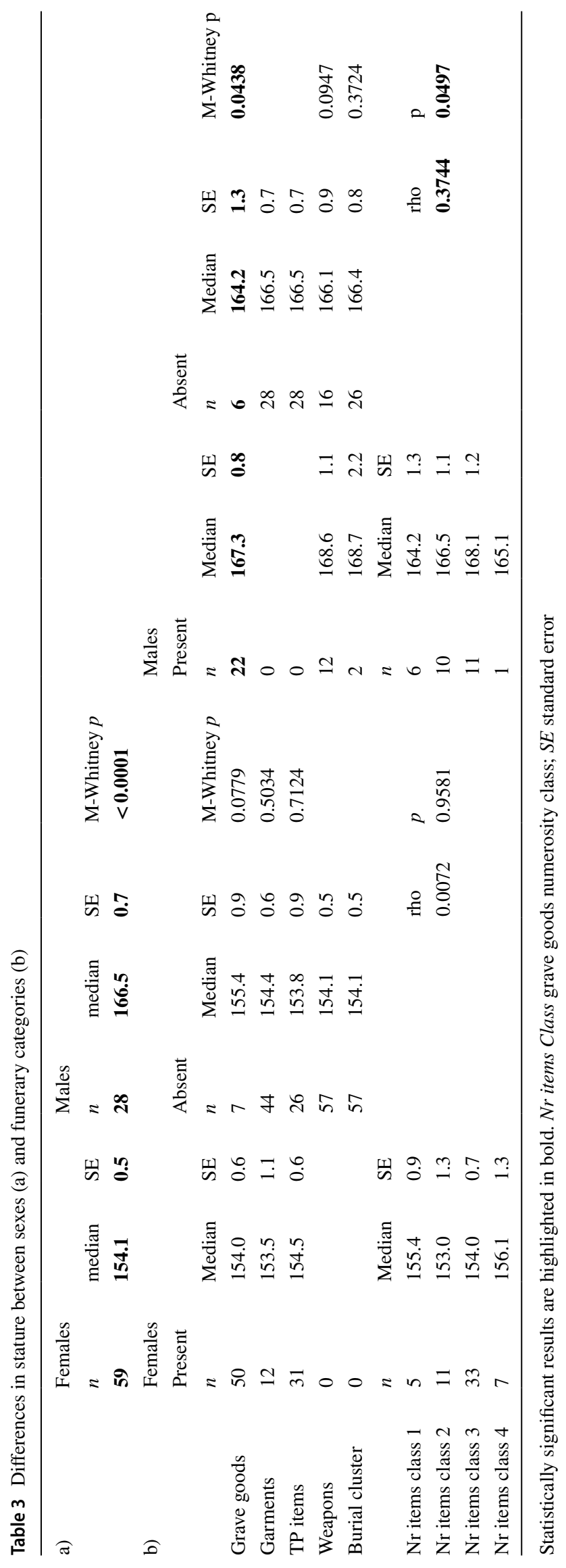

Springer 
Fig. 4 Frequencies of LEH ageat-onset (LEH OC) classes by age category. In females, older age classes are characterized by later age-at-onset of LEH
Females

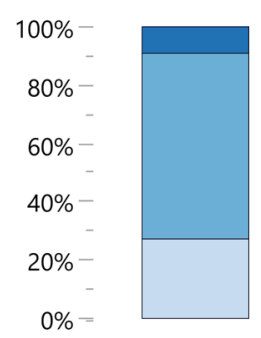

YA

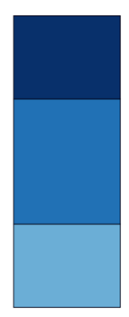

MA

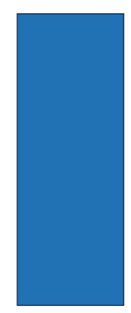

OA
Males

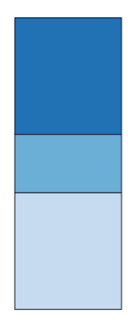

YA

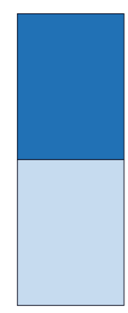

MA

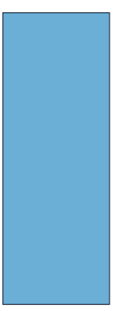

OA

\section{Non-adults}

$100 \%-$
$80 \%-$
$60 \%-$
-
$40 \%-$
$20 \%-$
-
$0 \%-$

$0 \%=$

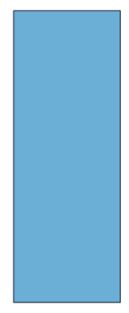

C

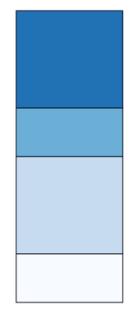

Ao $\square$ LEH OC1 (1-2y)

LEH OC2 (2-3y)

LEH OC3 (3-4y)

LEH OC4 (4-5y)

I

Grave goods

Specific costume

n: 35

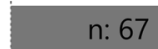

Textile production items
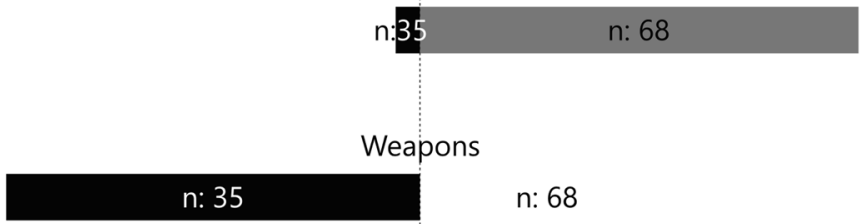

n: 68

$90 \%$

Fig. 5 Frequencies of funerary variables in the two sexes (number of funerary items not shown) 
Fig. 6 Stature by number of funerary items class. In males, stature tends to increase in parallel with the increase in funerary items

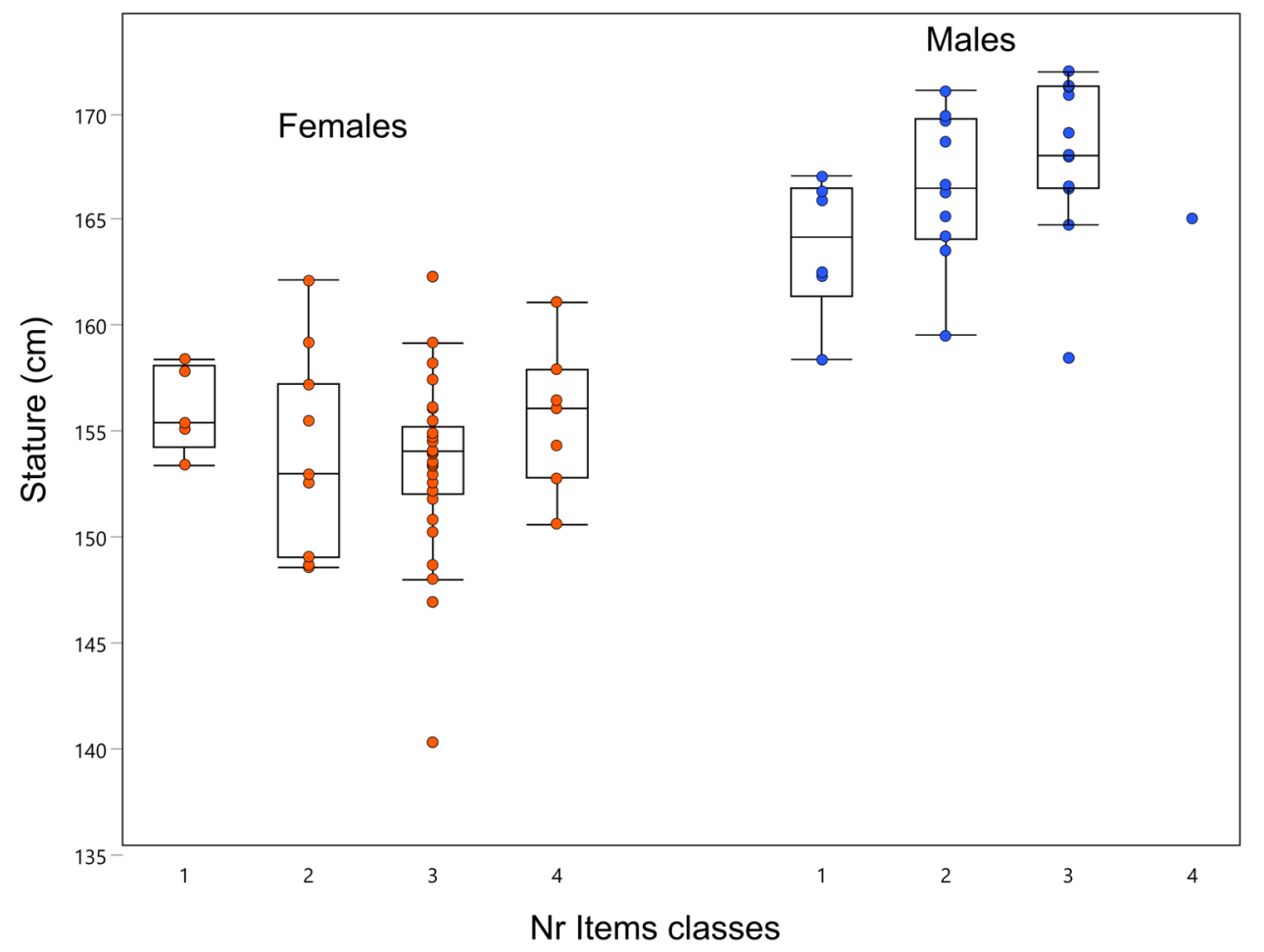

Conversely, sex influences all variables with the exception of the presence of grave goods (Fig. 5). Elaborate garments, textile production items, and number of grave good items are significantly associated to females. Weapons and deposition in a cluster are more frequent among males (Tables S1 and S2b). Males and females also differ in the number of funerary items (females in general having more numerous grave goods). The item numerosity classes 1 and 2 are more frequent in males, while classes 3 and 4 are more frequent in females (Table S2b).

\section{Paleopathological variables and stature vs. funerary treatment}

The previous analyses highlighted a heterogeneous distribution of biological and funerary variables across age classes, especially a sharp contrast between non-adults and adults. Non-adults show both a higher frequency of stress markers and a lower presence of grave goods. This result, likely due to the combination of different mortality risk following early life stressors and differential funerary treatment of nonadults (see also discussion), requires attention. Including non-adults in a combined analysis of biological and funerary variables would indeed raise the chance of observing (spurious) association between the presence of LEH, PH, and $\mathrm{CO}$ and the absence of funerary features. For this reason, we decided to exclude non-adults from this part of the study, which is therefore focused on the association between stress indicators and funerary differences among individuals who survived into adulthood.

LEH and CO are inversely associated with the presence of textile production items and elaborate garments, respectively (Table 4) (Tables S4b, S5, and S6).

Moreover, in adult males provided with grave goods are taller than those without ( $p: 0.04)$, and male stature increases together with the number of grave good items (rho: $0.4 ; p$ : 0.05 ) (Table 3; Fig. 6). Males with weapons are also taller than those without, but in this case, the difference does not reach statistical significance.

\section{Discussion}

\section{Limitations of the study}

Before discussing our results, it is important to consider a set of limitations affecting this study. These principally relate to (a) the actual information provided by the skeletal and dental variables used in our analyses, (b) the error associated with social reconstructions based on funerary data; (c) the complex link between social and biological status; and (d) the potential selective use of the analyzed necropolis.

First, we need to take into account the possible bias played on our results by the "osteological paradox" (Wood et al. 1992). In synthesis, it would be simplistic to assume a univocal relationship between the frequency of paleopathological variables and the actual health condition experienced 
Table 4 Results of logistic models with age and paleopathological variables as independent variables and funerary variables as outcomes

\begin{tabular}{|c|c|c|c|c|c|c|c|c|c|c|c|c|c|c|c|c|c|c|}
\hline \multirow[t]{2}{*}{ Adults } & \multicolumn{3}{|c|}{ Nr items } & \multicolumn{3}{|c|}{ Grave goods } & \multicolumn{3}{|c|}{ Garments } & \multicolumn{3}{|c|}{ TP items } & \multicolumn{3}{|c|}{ Weapons } & \multicolumn{3}{|c|}{ Burial cluster } \\
\hline & $\mathrm{DF}$ & Cs & $p$ & $\mathrm{DF}$ & Cs & $p$ & $\mathrm{DF}$ & Cs & $p$ & $\mathrm{DF}$ & Cs & $p$ & $\mathrm{DF}$ & Cs & $p$ & DF & Cs & $p$ \\
\hline Sex & 1 & 3.4 & 0.066 & 1 & 0.1 & 0.758 & 1 & 6.6 & 0.010 & 1 & 20.5 & $<.0001$ & 1 & $\mathbf{1 7 . 5}$ & $<.0001$ & 1 & 2.6 & 0.105 \\
\hline Age & 2 & 1.2 & 0.561 & 2 & 0.4 & 0.804 & 2 & 0.6 & 0.743 & 2 & 0.3 & 0.840 & 2 & 0.1 & 0.931 & 2 & 0.1 & 0.950 \\
\hline LEH & 1 & 0.2 & 0.651 & 1 & 0.0 & 0.846 & 1 & 0.5 & 0.477 & 1 & 4.3 & 0.039 & 1 & 0.4 & 0.532 & 1 & 0.6 & 0.431 \\
\hline NPL & 1 & 2.6 & 0.105 & 1 & 0.0 & 0.864 & 1 & 1.5 & 0.226 & 1 & 1.0 & 0.306 & 1 & 0.0 & 0.910 & 1 & 0.0 & 0.997 \\
\hline $\mathrm{CO}$ & 1 & 1.3 & 0.257 & 1 & 3.4 & 0.067 & 1 & 4.7 & 0.030 & 1 & 0.0 & 0.909 & 1 & 0.0 & 0.998 & 1 & 0.0 & 1.000 \\
\hline $\mathrm{PH}$ & 1 & 1.3 & 0.259 & 1 & 1.0 & 0.315 & 1 & 0.6 & 0.457 & 1 & 0.0 & 0.917 & 1 & 1.7 & 0.189 & 1 & 0.5 & 0.477 \\
\hline
\end{tabular}

Statistically significant results are highlighted in bold. $D F$ degrees of freedom; $C s$ residual deviance

by the population of Novilara. Heterogeneity in frailty, selective mortality, and genetic variability are likely to have shaped the observed mortality trend.

Moreover, LEH, CO, PH, and NPL can be influenced by different factors, or by the same factors (interplay between genetic, epigenetic, environmental etc.) but in different ways and with different timing (Cole and Waldron 2019; Mittler et al. 1992; Obertová and Thurzo 2008; Rivera and Mirazon Lahr 2017). This increase the "background noise" in our data, hampering the detection of more complex tendencies. Being limited to a discussion of unspecific stressors is especially a limit in a study like this. The relationship of these features to different etiological factors (e.g., nutritional, parasitic, infective, traumatic) would largely influence our definition of biological status and of its relationship with social status.

The resulting imprecision needs to be considered when testing the association between biological and social status. In our case, these problems are accentuated by the methods used in our study. We scored LEH, CO, PH, and NPL as binary variables and grouped age at onset of LEH in rough 1 -year classes. Moreover, we did not differentiate between single and multiple hypoplastic defects. This decision, while justified by our need to minimize possible errors or imprecise measurements, eliminates the possibility to distinguish between the single vs. repeated stressful episodes and to analyze enamel defects in teeth with different growth/eruption timing. The equations we used to estimate age at onset of LEH have been recently criticized due to the underlying assumption of a linear enamel growth rate during tooth formation. More recent alternatives include the decile method proposed by Reid and Dean $(2000,2006)$ and the exponential regression published by Cares Henriquez and Oxenham (2019). Note, however, that significant differences in age at onset between the Goodman and Rose's and Reid and Dean methods are in the range of 1 to 4 months (Martin et al. 2007; Ritzman et al. 2008). Since the aim of this study is not an in-depth analysis of diachronic patterns in developmental stress, we think that our estimates, even if possibly rough, are still adequate for our purposes.
Second, reconstructions of social status based on funerary data are complicated by specific features of each funerary context, and especially challenging for prehistoric settings like Novilara, where social differentiation, although likely present, may not be so obvious. In such situations, it may be tempting to apply subjective criteria in organizing the data for analysis, resulting in biased funerary variabilities. In our study, we tried to minimize this risk, but subjective biases are however still likely to have influenced our analysis. Moreover, social status is probably expressed not only along a vertical axis, but also horizontally. This, combined with the (admittedly rough) binary coding of funerary variables, is likely to mask the actual social variability and complexity in the analyzed context (see also Laffranchi et al. 2019). A similar issue affects the number of grave goods, which would be unwise to blindly identify as marker of status. Different objects have different economic and symbolic values, not necessarily related to hierarchical differences, and a single precious item may be more informative about status than several common objects (Cuozzo 1996; D'Agostino 1985; Parker Pearson 1982). In this study, we included this variable just to express a side of the funerary variability of Novilara, postponing any interpretation on its potential social meaning based on the analysis of the associated biological patterns.

Third, even in an ideal situation where both social and biological status can be archaeologically determined, the association between the two is likely to be influenced by additional variables (e.g., gender, age, geographic origin, chronological differences) (Robb et al. 2001). In addition, with the exception of NPL, the biological variables analyzed in our study provide information about exposure to stressors before adulthood. Conversely, if funerary treatment was actually related to social status, and the latter was acquired rather than inherited, funerary variability may be more informative about later phases of an individual life course.

Fourth, our analyses revealed a marked imbalance in the sex ratio (ca. 2:1 in favor of females). This result, by itself interesting, may suggest selective burial practices. When discussing our data, we need to be aware of this potential bias. 
Finally, we need to acknowledge the relatively small size of our sample, a limitation which becomes especially obvious when subdividing individuals between age classes and sexes. Although this is a common issue of osteoarchaeological samples, it calls for additional caution when trying to infer general biocultural patterns in our population.

The above considerations call for caution when discussing our results and highlight the unsuitability of straightforward interpretations and the need for a nuanced discussion. Nevertheless, our analyses do depict a number of interesting patterns and provide various, albeit preliminary, answers to our research questions. At the same time, the non-intuitive association between biological and social status needs to be kept at the center of the discussion.

\section{Paleopathological variables and stature vs. age-at-death and sex}

As mentioned, although the specific etiology of CO, LEH, and $\mathrm{PH}$ is unclear, they can provide information about exposure to early life stressors. Based on of previous studies, we would expect a decrease in the frequency of these features with advancing age (Steckel et al. 2002; Walker et al. 2009). Results generally agree with these expectations.

For $\mathrm{CO}$, the steady decrease in frequency with advancing age and the drop in the presence from adolescents to young adults find support in earlier studies which identified similar trends (Facchini et al. 2004; Steckel et al. 2002) and attributed them to the higher exposure of the youngest individuals to environmental stressors. Interestingly, age trajectories of $\mathrm{PH}$ do not align with those of $\mathrm{CO}$. This result supports earlier claims about different etiologies of these conditions, which justifies our choice to analyze them separately (Brickley 2018; Rivera and Mirazon Lahr 2017; Walker et al. 2009).

While age-related patterns of $\mathrm{CO}$ and $\mathrm{PH}$ do not deviate from expectations based on previous studies, results on LEH are particularly interesting due to their complexity.

Life history traits (e.g., weaning period), environmental (relative exposure to pathogens), and cultural (socioeconomic systems) factors can influence the incidence and timing of enamel hypoplasia (Goodman and Rose 1991; Larsen 2015). Previous discussions of LEH in archaeological samples have invoked the weaning phase and post-weaning stress as the main factors responsible for the emergence of hypoplastic defects (e.g., Corruccini et al. 1985; Goodman et al. 1987), a conclusion mitigated by other researchers who signaled the more likely contribution of additional factors (Ham et al. 2020; Kyle et al. 2020; Towle and Irish 2020).

The peak in frequency of LEH in adolescents combined with the positive correlation between age-at-onset and ageat-death point to a link between early life stressors and mortality risk. It is also interesting that the frequency of LEH decreases in adults from YA to OA. Although this may be related to the long-term effect of early life stressors resulting in a shorter life expectancy (Boldsen 2007), additional causes cannot be excluded (e.g., cumulative adversity - Amoroso et al. 2014). In the future, more focused analyses will allow to better explore this aspect of the Novilara population.

The etiology of NPL includes nutritional, environmental, physiological, and biomechanical factors (Klaus and Tam, 2009; Larsen 1997). Previous studies highlighted a variable association between this feature and age (e.g., Larsen et al. 2015; Ślaus 2008; Zoëga and Murphy 2016), a likely result of the various types of inflammatory processes responsible for this feature. In our case, the increase of NPL with age points to biomechanical processes as the main factor responsible for the observed patterns (accumulation of localized microtraumatic events throughout life) rather than to infectious processes. A probable explanation is that individuals sustaining infectious processes simply died before they had time to develop observable periosteal reactions. Naturally, we cannot exclude that NPL in adults may be at least in part related to earlier infections which the individual survived.

If the culture of Novilara envisioned a different parental investment on male vs. female offspring, we would expect an association between sex and paleopathological variables in our data. Results show however no such association, suggesting similar exposures to environmental stressors for males and females. Similar patterns were observed among other Iron Age populations such as the Etruscan-Samnites from Pontecagnano (Salerno, 7th-5th c. BC) especially for porotic hyperostosis and periostitis (Sonego and Scarsini 1994) and the Etruscans from Spina (Ferrara, 6th-3rd c. BC) for cribra orbitalia, porotic hyperostosis, and periostitis (Manzon and Gualdi-Russo 2016). Based on our data, we cannot exclude dietary differences between the men and women of Novilara, nor subtle differences in their living conditions. It is also important to note that we did not attempt to determine sex of non-adults. This means that our data likely describe only part of the actual variation of paleopathological variables according to sex. It is important to keep in mind that in the anthropological examination of skeletal remains we are facing with sex differences, which are conceptually distinct from gender patterns, the latter referring to culturally constructed social identities (Agarwal and Wesp 2017; Zuckerman and Crandall 2019). Gender roles in the society at Novilara are clearly represented in funerary rituals (see below), and a gender subdivision of labor has been preliminarily suggested based on sex-specific frequencies of non-masticatory dental wear in individuals excavated during the nineteenth century (Consiglio 2008: 419). Based on our results, it seems however that this did not translate into sharp differences in health status between sexes. This type of inference needs to be considered with caution though due 
to the uncertain overlap between biological sex and gender (see Zuckerman and Crandall 2019; Walker and Cook 1998).

\section{Age-at-death, sex, and funerary treatment}

In general, our analyses point to the importance of age and especially sex as driving factors behind funerary variability at Novilara. Moreover, our results provide additional insights into possible life course and sex-related patterns of social identity in the analyzed population. As already mentioned, simplistic interpretations of funerary features are in most cases inadvisable (Härke 2000; Laffranchi et al. 2021; Robb et al. 2001). Similarly, biological sex is not necessarily synonymous with gender identity (Walker and Cook 1998), and this is an often-mentioned limitation of archaeological discussions of gender differences based on sex-related differences of archaeological and skeletal variables (Zuckerman and Crandall 2019). While these caveats also need to be considered in the present study, the marked demographic variability characterizing funerary features strongly suggests an intersection between sex, age, and social identity in this community. This is especially indicated by the sudden change in the amount of grave goods and the appearance of "genderized" items (e.g., elaborate garments, weapons) after adolescence.

The sharp separation of these funerary variables between sexes and the larger number of grave goods in female burials are common patterns in other Picene necropoles (Delpino et al. 2016) which indicates a strong gender differentiation and the idealized association of specific objects and activities to women and men.

Similar funerary patterns are also highlighted in a bioarchaeological study of a subsample from Pontecagnano (Southern Italy, 5th-3rd c. BC) (Robb 2019). Previous hypotheses postulated a link between the spatial organization of Novilara (funerary clusters) and some type of inherited status (e.g., familiar or other forms of kinship - Beinhauer 1985; Delpino 2018). This is particularly evident from the beginning of the seventh century $\mathrm{BC}$, with the change of the status of some children through the formalization of hereditary wealth and social status (Delpino 2018). Sample preservation hampered tests of kinship patterns across closely spaced burials or "Groups" (see Fig. S1 and supplemental information in Serventi et al. 2018). Our analyses do not help to clarify the meaning of this funerary organization. The larger proportion of males in clusters may indeed be biased by the small number of male individuals in the analyzed skeletal sample and the lack of information about the sex of the non-adults.

Grave good variability at Novilara is clearly related to the age of the individual, at least until adolescence. Non-adults are provided with grave goods (e.g., ceramic vessels, personal ornaments) only starting from ca. 1-2 years of age, a possible sign of a culturally sanctioned age threshold toward their inclusion in the social group. A second age threshold is signaled by the appearance of gender-specific items in the burials of young adults. Another potentially interesting pattern is the apparent increase of the presence of textile production items with advancing age in females, which is however not statistically significant.

\section{Paleopathological variables, stature, and funerary treatment}

The third part of this study aimed to test if exposure to stressors during growth was linked to social status (at the moment of death). If for example some individuals were less exposed to early life health insults due to their social status, we would expect to find an association between paleopathological, stature and funerary variables.

Our results partially agree with this expectation. The inverse association in adults between LEH and textile production items, $\mathrm{CO}$ and elaborate garments, and the larger stature of male individuals with grave goods and with more numerous funerary items may indeed suggest an association between biological and social status at Novilara, as expected based on a theoretical lower risk for chronic or infectious diseases (Cohen 1999) and malnutrition episodes (Van de Poel et al. 2008) in individuals of a "higher economic and social status" (Peck 2013) and, potentially, of their better diet. Note, however, that the lower frequency of paleopathological features in a specific group is not necessarily a sign of their better health. Rather, it may well be that these individuals simply died before the stressors had the time to leave their traces on the skeletal system (Wood et al. 1992). It is in any case interesting that at Novilara male individuals with weapons are also on average taller than those without (although the difference does not reach statistical significance). This result may be related to a privileged social status of these men presented in death as warriors. The importance of warfare in the society of Novilara has been also cited by Brasili et al. (2004), when discussing the frequency and type of cranial lesions in the skeletons excavated during the nineteenth century, and recently by Beck De Lotto and colleagues (2018), in their analysis of inflicted traumas in the skeletal remains from the 2012 to 2013 investigations.

Data from another Iron Age context of Italy (Pontecagnano -7 th-3rd c. BC) highlighted no association between funerary treatment and skeletal features (e.g., stature, enamel hypoplasia, and cribra orbitalia) (Robb et al. 2001). Similar results were also obtained in a study of a Middle Iron Age population (400-100 BC) from Northern England (Peck 2013). In this case, skeletal markers did not differ between "elite" and "non-elite" individuals. Conversely, Sparacello et al. (2017) found a significant positive correlation between stature and socioeconomic status expressed by funerary 
features only among males and only for a specific period (800-500 BC) when analyzing several Iron Age necropolises from Abruzzo (Central Italy). For Novilara, it is important to consider that various biological variables (e.g., stature in females, paleopathological variables in males) do not show any clear patterning according to funerary treatment. This, in conjunction with the heterogeneous results obtained from the cited studies, can firstly be linked to theoretical limitations (see above). Secondly, the diversified results of our study demonstrate that the association between social and biological status at Novilara was rather complex and multifaceted. Social differentiation and living conditions in this Iron Age population were not straightforwardly associated, but rather differently intertwined across sexes and age.

\section{Conclusion}

Our results highlight some important patterns related to the association between social and biological status in the population of Novilara. In general terms, it appears that the increasing complexity of funerary treatment was negatively associated to the experience of stressful living conditions. Our data suggest the presence of a complex influence of social differentiation on the living condition of this population and that such influence strongly varied based on sex, age, type, and quantity of experienced stressors. This study demonstrates the challenges involved in the reconstruction of social and biological status, and of their possible links, among past populations. The results of our analyses suggest the presence of a complex influence of social differentiation upon the lives of the people buried at Novilara and that such influence strongly varied based on sex, age, and the type and quantity of experienced stressors. The dental and skeletal variables used in this study provide only non-specific information about environmental stressors experienced by this population. Similarly, our funerary variables can only (and cautiously) be linked to rough patterns of social differentiation. These considerations suggest the need for additional analyses in order to better quantify the biological and social variability characterizing this population.

Planned analyses include an extensive isotopic study (carbon, nitrogen, sulfur, oxygen, and strontium) aimed at reconstructing diet and mobility, and their possible link to social differentiation, as well as additional aDNA analyses. The latter will provide further insights into kinship patterns as well as biological affinities with other protohistoric and historic populations from the Italian Peninsula and the Mediterranean area.

Supplementary Information The online version contains supplementary material available at https://doi.org/10.1007/s12520-021-01449-3.
Acknowledgements The authors thank the Editor and the two anonymous reviewers whose comments greatly enhanced the scientific quality of the present contribution. They also want to thank the Superintendence for the Cultural Heritage of the Marche Region (Italian Ministry of Culture), on behalf of which the 2012-2013 excavations were directed. ZL was supported by the project NeArqBioSI (A.HUM.460.UGR18), Operational Program FEDER-2018 of the "Junta de Andalucia," Spain and by a Swiss National Science Foundation grant to MM (nr: 10531FL_197103/1). Thanks to Christine Cooper for proofreading the English version of this manuscript.

Author contribution Zita Laffranchi: Conceptualization, methodology, data collection and curation, investigation, writing-original draft, and writing-review and editing.

Michael A. Beck De Lotto: Conceptualization, methodology, data collection and curation, investigation, and writing-review and editing.

Chiara Delpino: Conceptualization, supervision, resources, data collection and curation, and writing-review and editing.

Sandra Lösch: Supervision, and writing-review and editing.

Marco Milella: Conceptualization, methodology, validation, formal analysis, supervision, writing-original draft, and writing-review and editing.

Funding Open access funding provided by University of Bern. The restoration of the archaeological finds from Novilara was performed in the frame of the "Progetto di restauro degli oggetti di corredo rinvenuti nella necropoli picena di Novilara" (Swiss Federal Office of Culture) and with the additional financial support of Fondazione Scavolini (Italy).

Data availability The data that support the findings of this study are available from the corresponding author upon request.

Code availability Not applicable.

\section{Declarations}

Conflict of interest The authors declare no competing interests.

Open Access This article is licensed under a Creative Commons Attribution 4.0 International License, which permits use, sharing, adaptation, distribution and reproduction in any medium or format, as long as you give appropriate credit to the original author(s) and the source, provide a link to the Creative Commons licence, and indicate if changes were made. The images or other third party material in this article are included in the article's Creative Commons licence, unless indicated otherwise in a credit line to the material. If material is not included in the article's Creative Commons licence and your intended use is not permitted by statutory regulation or exceeds the permitted use, you will need to obtain permission directly from the copyright holder. To view a copy of this licence, visit http://creativecommons.org/licenses/by/4.0/.

\section{References}

Acsádi G, Nemeskéri J (1970) History of human life span and mortality. Akadémiai Kiadó, Budapest

Amoroso A, Garcia SJ, Cardoso HF (2014) Age at death and linear enamel hypoplasias: testing the effects of childhood stress and adult socioeconomic circumstances in premature mortality. Am J Hum Biol 26(4):461-468. https://doi.org/10.1002/ajhb.22547 
Agarwal SC, Wesp JK (2017) Exploring sex and gender in bioarchaeology. University of New Mexico Press, Albuquerque, NM

Baldelli G (1982) La stele di Novilara, in Novilara. Le necropoli dell'età del Ferro. Pesaro

Beck De Lotto MA, Laffranchi Z, Delpino C (2018) Inflicted trauma among the Piceni population from Iron Age necropolis of Novilara (Italy - Pesaro, 8th-7th c. BC. Paper presented at the 22nd European Meeting of the Paleopathology Association, Zagreb, 28th August-1st September

Beinhauer KW (1985) Untersuchungen zu den eisenzeitlichen Bestattungsplätzen von Novilara (Provinz Pésaro und Urbino, Italien): Archäologie-Anthropologie-Demographie; Methoden und Modelle. 2. Listen-Ortsverzeichnis. . Haag + Herchen, Frankfurt am Main

Bietti Sestieri AM (1992) The Iron age community of Osteria dell'Osa: a study of sociopolitical development in central Tyrrhenian Italy. Cambridge University Press, Cambridge

Boldsen JL (2007) Early childhood stress and adult age mortality-a study of dental enamel hypoplasia in the medieval Danish village of Tirup. Am J Phys Anthropol 132(1):59-66. https://doi. org/10.1002/ajpa.20467

Brasili P, Bianchi E, Ventrella AR (2004) Traumatic events and lifestyle in ancient Italian populations. Coll Anthropol 28:179-191

Brickley MB (2018) Cribra orbitalia and porotic hyperostosis: a biological approach to diagnosis. Am J Phys Anthropol 167:896902. https://doi.org/10.1002/ajpa.23701

Brizio E (1895) La Necropoli di Novilara presso Pesaro., vol Monumenti Antichi. R. Accademia dei Lincei, Roma

Brooks S, Suchey JM (1990) Skeletal age determination based on the os pubis: a comparison of the Acsádi-Nemeskéri and Suchey-Brooks methods. Hum Evol 5:227-238. https://doi.org/10.1007/BF02437238

Buikstra J, Ubelaker DH (1994) Standards for data collection from human skeletal remains. Arkansas Archaeological Service, Fayetteville AR

Cares Henriquez A, Oxenham MF (2019) New distance-based exponential regression method and equations for estimating the chronology of linear enamel hypoplasia (LEH) defects on the anterior dentition. Am J Phys Anthropol. 168(3): 510-520. https://doi.org/10.1002/ajpa.23764

Cohen MN, Armelagos GJ (1984) Paleopathology at the origins of agriculture. Academic Press, Orlando

Cohen MN, Crane-Kramer G (2007) Ancient health: Skeletal indicators of agricultural and economic intensification. Bioarchaeological interpretations of the human past: local, regional, and global perspectives series. University Press of Florida, Gainesville, FL

Cohen S (1999) Social status and susceptibility to respiratory infections. Ann N Y Acad Sci 896:246-253

Cole G, Waldron T (2019) Cribra Orbitalia: Dissecting an Ill-Defined Phenomenon Int J Osteoarchaeol 29:613-621. https://doi.org/ 10.1002/oa.2757

Consiglio C (2008) Non masticatory dental lesions in the study of biology and behaviour of ancient populations: the contribution of the stereomicroscopy and scanning electron microscopy. $\mathrm{PhD}$ dissertation, University of Bologna

Corruccini R, Handler J, Jacobi K (1985) Chronological distribution of enamel hypoplasias and weaning in a Caribbean slave population. Hum Biol 57:699-711

Cuozzo M (1996) Prospettive teoriche e metodologiche nell'interpetazione delle necropoli: la Post-Processual Archaeology. Annali Dell'istituto Orientale Di Napoli - Archeologia e Storia Antica 3:1-38

Cuozzo M (2000) Orizzonti teorici e interpretativi, tra percorsi di matrice francese, archeologia post-processuale e tendenze italiane: considerazioni e indirizzi di ricerca per lo studio delle necropoli. In: Terrenato N (ed) Archeologia teorica. All'Insegna del Giglio, Firenze, pp 323-360
D'Agostino B (1985) Società dei vivi, comunità dei morti: un rapporto difficile Dialoghi di Archeologia 3:47-58

Delpino C (2018) Infant and child burials in the Picene necropolis of Novilara (Pesaro): the 2012-2013 excavations. . In: Tabolli J (ed) From Invisible to Visible New Methods and Data for the Archaeology of Infant and Child Burials in Pre-Roman Italy and Beyond. vol Studies in Mediterranean Archaeology. Astrom Editions, Nicosia, pp 123-133

Delpino C, Finocchi S, Postrioti G (2016) Necropoli del Piceno Dati acquisiti e prospettive di ricerca In: Baldini G, Giroldini P (eds) Dalla Valdelsa al Conero Ricerche di archeologia e topografia storica in ricordo di Giuliano de Marinis, All'Insegna del Giglio, San Gimignano - Poggibonsi vol 2, pp 287-304

Facchini F, Rastelli E, Brasili P (2004) Cribra orbitalia and cribra cranii in Roman skeletal remains from the Ravenna area and Rimini(I-IV century AD). Int J Osteoarchaeol 14:126-136. https://doi.org/10.1002/oa.717

Ferembach D, Schwidetzky J, Stloukal M (1980) Recommendations for age and sex diagnoses of skeletons. J Hum Evol 9:517-549

Goodman AH, Allen LH, Hernandez GP, Amador A, Arriola LV, Chavez A, Pelto GH (1987) Prevalence and age at development of enamel hypoplasias in Mexican children. Am J Phys Anthropol 72:7-19. https://doi.org/10.1002/ajpa.1330720103

Goodman AH, Rose JC (1990) Assessment of systemic physiological perturbations from dental enamel hypoplasias and associated histological structures. Yearb Phys Anthropol 33:59-110. https://doi.org/10.1002/ajpa.1330330506

Goodman AH, Rose JC (1991) Dental enamel hypoplasias as indicators of nutritional status. In: Kelley M, Larsen CS (eds) Advances in dental anthropology. Wiley-Liss, New York, pp 279-293

Ham AC, Temple DH, Klaus HD, Hunt DR (2020) Evaluating life history trade-offs through the presence of linear enamel hypoplasia at Pueblo Bonito and Hawikku: a biocultural study of early life stress and survival in the ancestral Pueblo Southwest. Am J Hum Biol:e23506. https://doi.org/10.1002/ajhb.23506

Härke H (2000) Social analysis of mortuary evidence in German protohistoric archaeology JAnthropol. Archaeol 19:369-384. https://doi.org/10.1006/jaar.2000.0364

Hengen OH (1971) Cribra orbitalia: pathogenesis and probable etiology. Homo 22:57-76

Işcan MY, Loth SR, Wright RK (1984) Metamorphosis at the sternal rib end: a new method to estimate age at death in white males. Am J Phys Anthropol 65:147-156. https://doi.org/10.1002/ajpa. 1330650206

Işcan MY, Loth SR, Wright RK (1985) Age estimation from the rib by phase analysis: white females. J Forensic Sci 30:853-863

King SE, Ulijaszek SJ (1999) Invisible insults during growth and development: contemporary theories and past populations. In: Hoppa RD, FitzGerald CM (eds) Human growth in the past: studies from bones and teeth. Cambridge University Press, Cambridge, pp 161-182

Klaus HD, Tam ME (2009) Contact in the Andes: bioarchaeology of systemic stress in colonial Mórrope, Peru. Am J Phys Anthropol 138:356-368. https://doi.org/10.1002/ajpa.20944

Klaus HD (2017) Paleopathological rigor and differential diagnosis: case studies involving terminology, description, and diagnostic frameworks for scurvy in skeletal remains. Int Paleopathol 19:96-110. https://doi.org/10.1016/j.ijpp.2015.10.002

Kyle B, Shehi E, Koci M, Reitsema LJ (2020) Bioarchaeological reconstruction of physiological stress during social transition in Albania. Int J Paleopathol 30:118-129. https://doi.org/10. 1016/j.ijpp.2020.06.003

Laffranchi Z, Cavalieri Manasse G, Salzani L, Milella M (2019) Patterns of funerary variability, diet, and developmental stress in 
a Celtic population from NE Italy (3rd-1st c BC). PLoS One 14:e0214372. https://doi.org/10.1371/journal.pone.0214372

Laffranchi Z, Milella M, Lombardo P, Langer R, Losch S (2021) Cooccurrence of malignant neoplasm and hyperostosis frontalis interna in an Iron Age individual from Munsingen-Rain (Switzerland): a multi-diagnostic study. Int J Paleopathol 32:1-8. https://doi.org/10.1016/j.ijpp.2020.10.008

Larsen CS (1997). Bioarchaeology: Interpreting behavior from the human skeleton. Cambridge University Press, Cambridge, UK.

Larsen CS (2015) Bioarchaeology. Interpreting behaviour from the human skeleton, 2nd edition. Cambridge University Press, Cambridge. https://doi.org/10.1017/CBO9781139020398

Larsen CS, Hillson SW, Boz B, Pilloud MA, Sadvari JW, Agarwal SC, Glencross B, Beauchesne P, Pearson J, Ruff CB, Garofalo EM, Hager LD, Haddow SD, Knüsel CJ (2015) Bioarchaeology of Neolithic Çatalhöyük: Lives and lifestyles of an early farming society in transition. J World Prehist 28: 27-68.https://doi. org/10.1007/s10963-015-9084-6

Larsen CS (2006) The changing face of bioarchaeology: an interdisciplinary science. In: Buikstra JE, Beck LA (eds) Bioarchaeology: the contextual analysis of human remains. Academic Press, Amsterdam, pp 359-374

Lê S, Josse J, Husson F (2008) FactoMineR: AnRPackage for Multivariate Analysis. J Stat Softw 25. https://doi.org/10.18637/ jss.v025.i01

Lovejoy CO, Meindl RS, Pryzbeck TR, Mensforth RP (1985) Chronological metamorphosis of the auricular surface of the ilium: a new method for the determination of adult skeletal age at death. Am J Phys Anthropol 68:15-28. https://doi.org/10.1002/ajpa. 1330680103

Lollini DG (1976) La civiltà picena. In: Cianfarani V, Lollini D, Zuffa M (eds) Popoli e civiltà dell'Italia antica vol 5, Roma, pp 109-195.

Maat GJR (2005) Two millennia of male stature development and population health and wealth in the Low Countries. Int J Osteoarchaeol 15:276-290. https://doi.org/10.1002/oa.785

Manzi G, Salvadei L, Vienna A, Passarello P (1999) Discontinuity of life conditions at the transition from the Roman imperial age to the early middle ages: example from central Italy evaluated by pathological dento-alveolar lesions. Am J Hum Biol 11:327-341. https://doi.org/10.1002/(SICI)1520-6300(1999) 11:3\%3C327::AID-AJHB5\%3E3.0.CO;2-M

Manzon VS, Gualdi-Russo E (2016) Health patterns of the etruscan population (6th-3rd centuries bc) in Northern Italy: The Case of Spina. Int J Osteoarchaeol 26:490-501. https://doi.org/10. 1002/oa.2438

Marmot M, Bell R (2016) Social inequalities in health: a proper concern of epidemiology. Ann Epidemiol 26:238-240. https://doi. org/10.1016/j.annepidem.2016.02.003

Martin SA, Guatelli-Steinberg D, Sciulli PW, Walker PL (2007) Brief communication: Comparison of methods for estimating chronological age at linear enamel formation on anterior dentition. Am J Phys Anthropol 135:362-365. https://doi.org/10.1002/ ajpa.20725

McFadden C, Oxenham MF (2020) A paleoepidemiological approach to the osteological paradox: investigating stress, frailty and resilience through cribra orbitalia. Am J Phys Anthropol 173:205-217. https://doi.org/10.1002/ajpa.24091

Mieklejohn C, Babb J (2011) Long bone length, stature and time in the European Late Pleistocene and Early Holocene. In: Pinhasi R, Stock JT (eds) Human Bioarchaeology of the Transition to Agriculture. Wiley, Chichester, pp 151-175. https://doi.org/10. 1002/9780470670170

Minozzi S, Caldarini C, Pantano W, Giannantonio S, Catalano P, Giuffra V (2020) Enamel hypoplasia and health conditions through social status in the Roman Imperial age (first to third centuries, Rome, Italy). Int J Osteoarchaeol 30:53-64. https:// doi.org/10.1002/oa.2830

Mittler D, Van Gerven D, Sheridan S, Beck R (1992) The epidemiology of enamel hypoplasia, cribra orbitalia, and subadult mortality in an ancient Nubian population. In: Goodman A, Capasso L (eds) Recent Contributions to the Study of Enamel Developmental Defects vol 2. Journal of Paleopathology Monographic Publications 2. , Edigrafital Teramo, Chieti, pp 143-150

Mummert A, Esche E, Robinson J, Armelagos GJ (2011) Stature and robusticity during the agricultural transition: evidence from the bioarchaeological record. Econ Hum Biol 9:284-301. https:// doi.org/10.1016/j.ehb.2011.03.004

Naso A (2000) I Piceni.Storia e archeologia delle Marche in epoca pre-Romana vol 29. Biblioteca di Archeologia. Longanesi \& C, Milano

Nguyen V-K, Peschard K (2003) Anthropology, inequality, and disease: a review. Annu Rev Anthropol 32:447-474. https://doi. org/10.1146/annurev.anthro.32.061002.093412

O'Donnell L, Hill EC, Anderson ASA, Edgar HJH (2020) Cribra orbitalia and porotic hyperostosis are associated with respiratory infections in a contemporary mortality sample from New Mexico Am J Phys Anthropol. https://doi.org/10.1002/ajpa. 24131

Obertová Z, Thurzo M (2008) Relationship between cribra orbitalia and enamel hypoplasia in the early medieval Slavic population at Borovce, Slovakia. Int J Osteoarchaeol 18:280-292. https:// doi.org/10.1002/oa.937

Ortner DJ (2003) Identification of pathological conditions in human skeletal remains, 2nd edn. Academic press, San Diego

Parker Pearson M (1982) Mortuary practices, society and ideology: an ethnoarchaeological study. In: Hodder I (ed) Symbolic and structural archaeology. Cambridge University Press, Cambridge, pp 99-114. https://doi.org/10.1017/CBO9780511 558252.011

Parker Pearson M (1993) The powerful dead: archaeological relationships between the living and the dead. Camb Archaeol J 3:203-229. https://doi.org/10.1017/S0959774300000846

Pearson K (1899) Mathematical contributions to the theory of evolution.- V. On the reconstruction of the stature of prehistoric races philosophical transactions of the royal society of London series a, Containing Papers of a Mathematical or Physical Character 192:169-244. https://doi.org/10.1098/rsta. 1899.0004

Pechenkina EA, Delgado M (2006) Dimensions of health and social structure in the early intermediate period cemetery at Villa El Salvador. Peru Am J Phys Anthropol 131:218-235. https://doi. org/10.1002/ajpa.20432

Peck JJ (2013) Status, health, and lifestyle in Middle Iron Age Britain: a bioarcheological study of elites and non-elites from East Yorkshire. Northern England Int J Paleopathol 3:83-94. https:// doi.org/10.1016/j.ijpp.2013.03.005

Phenice TW (1969) A newly developed visual method of sexing the os pubis. Am J Phys Anthropol 30:297-301. https://doi.org/10. 1002/ajpa.1330300214

Pindborg JJ (1970) Pathology of the dental hard tissues. Saunders, Philadelphia

Pindborg JJ (1982) Aetiology of developmental enamel defects not related to fluorosis. Int Dent J 32:123-134

R Core Team (2021) R: A language and environment for statistical computing. R Foundation for Statistical Computing. https:// www.R-project.org/. Accessed 3 May 2021.

Rathbun RH, Steckel JC (2003) Patterns of health in Western hemisphere. In: Steckel RH, Rose JC (eds) The backbone of history. Cambridge University Press, Cambridge, pp 563-579

Reid DJ, Dean MC (2000) Brief communication: the timing of linear hypoplasias on human anterior teeth. Am J Phys Anthropol 
11:135-139. https://doi.org/10.1002/1096-8644(200009)

113:1\%3C135::AID-AJPA13\%3E3.0.CO;2-A

Reid DJ, Dean MC (2006) Variation in modern human enamel formation times. J Hum Evol 50:329-346. https://doi.org/10.1016/j. jhevol.2005.09.003

Reitsema LJ, Vercellotti G (2012) Stable isotope evidence for sex- and status-based variations in diet and life history at medieval Trino Vercellese. Italy Am J Phys Anthropol 148:589-600. https://doi. org/10.1002/ajpa.22085

Ritzman TB, Baker BJ, Schwartz GT (2008) A fine line: a comparison of methods for estimating ages of linear enamel hypoplasia formation. Am J Phys Anthropol 135:348-361. https://doi.org/ 10.1002/ajpa.20750

Rivera F, Mirazon Lahr M (2017) New evidence suggesting a dissociated etiology for cribra orbitalia and porotic hyperostosis. Am J Phys Anthropol 164:76-96. https://doi.org/10.1002/ajpa.23258

Robb J (1997) Violence and gender in early Italy. In: Martin DL, Frayer DW (eds) Troubled Times Violence and Warfare in the Past. Gordon and Breach Publishers, pp 111-144

Robb J (2019) Beyond individual lives: using comparative osteobiography to trace social patterns in classical Italy. Bioarchaeol Int 3:58-77. https://doi.org/10.5744/bi.2019.1008

Robb J, Bigazzi R, Lazzarini L, Scarsini C, Sonego F (2001) Social "status" and biological "status": a comparison of grave goods and skeletal indicators from Pontecagnano. Am J Phys Anthropol 115:213-222. https://doi.org/10.1002/ajpa.1076

Roberts CA (2019). Infectious disease: introduction, periostosis, periostitis, osteomyelitis, and septic arthritis. In Buikstra JE (ed) Ortner's Identification of Pathological Conditions in Human Skeletal Remains (Third Edition), Academic Press, pp 285-319. https:// doi.org/10.1016/C2011-0-06880-1

Sarnat BG, Schour I (1941) Enamel hypoplasia (chronologic enamel aplasia) in relation to systemic disease: a chronologic, morphologic and etiologic classification. J Am Dent Assoc 28:1989-2000

Schaefer M, Black S, Scheuer L (2009) Juvenile osteology. A laboratory and field manual. Academic Press, London

Scheuer L, Black S (2000) Developmental juvenile osteology. Academic Press, New York. https://doi.org/10.1016/B978-0-12624000-9.X5000-X

Sergi G (1907) I sepolcreti di Novilara (Pesaro) Atti della Società romana di antropologia XIII:3-16

Serventi P, Panicucci C, Bodega R et al (2018) Iron Age Italic population genetics: the Piceni from Novilara (8th-7th century BC). Ann Hum Biol 45:34-43. https://doi.org/10.1080/03014460. 2017.1414876

Shin DH, Oh CS, Kim YS, Hwang YI (2012) Ancient-to-modern secular changes in Korean stature. Am J Phys Anthropol 147:433442. https://doi.org/10.1002/ajpa.22011

Silventoinen K, Sammalisto S, Perola M et al (2012) Heritability of adult body height: a comparative study of twin cohorts in eight countries. Twin Res 6(5):399-408. https://doi.org/10.1375/ twin.6.5.399

Silvestrini M, Sabbatini T (2008) Potere e Splendore. Gli Antichi Piceni a Matelica. L'Erma di Bretschneider, Roma

Slaus M (2008) Osteological and dental markers of health in the transition from the Late Antique to the Early Medieval period in Croatia. Am J Phys Anthropol 136:455-469. https://doi.org/10. 1002/ajpa.20829

Smith-Guzman NE (2015) Cribra orbitalia in the ancient Nile Valley and its connection to malaria. Int J Paleopathol 10:1-12. https:// doi.org/10.1016/j.ijpp.2015.03.001

Smith HB (1984) Patterns of molar wear in hunter-gatherers and agriculturalists. Am J Phys Anthropol 63:39-56. https://doi.org/10. 1002/ajpa.1330630107
Smith MO, Kurtenbach KJ, Vermaat JC (2016) Linear enamel hypoplasia in Schroeder Mounds (11HE177): a late woodland period site in Illinois. Int J Paleopathol 14:10-23. https://doi.org/10. 1016/j.ijpp.2016.04.005

Sonego F, Scarsini C (1994) Indicatori scheletrici e dentari dello stato di salute e delle condizioni di vita a Pontecagnano (Salerno) nel VII-V sec. a.C. Bullettino Di Paletnologia Italiana 85:449-473

Sorrentino R, Bortolini E, Lugli F et al (2018) Unravelling biocultural population structure in $4 \mathrm{th} / 3$ rd century BC Monterenzio Vecchio (Bologna, Italy) through a comparative analysis of strontium isotopes, non-metric dental evidence, and funerary practices. PLoS One 13:e0193796. https://doi.org/10.1371/journal.pone.0193796

Sparacello VS, d'Ercole V, Coppa A (2015) A bioarchaeological approach to the reconstruction of changes in military organization among Iron Age Samnites (Vestini) From Abruzzo Central Italy. Am J Phys Anthropol 156:305-316. https://doi.org/10. 1002/ajpa.22650

Sparacello VS, Vercellotti G, d'Ercole V, Coppa A (2017) Social reorganization and biological change: an examination of stature variation among Iron Age Samnites from Abruzzo, central Italy. Int J Paleopathol 18:9-20. https://doi.org/10.1016/j.ijpp.2017.07.003

Steckel JC, Sciulli PW, Rose JC (2002) A health index from skeletal remains. In: Steckel JC, Rose JC (eds) The backbone of history: health and nutrition in the Western Hemisphere. Cambridge University Press, New York

Steckel RH, Larsen CS, Sciulli PW, Walker PL (2006) Data collection codebook. The Global History of Health Project. https://www. uv.es/paleolab/Codebook-08-25-051\%5B1\%5D.pdf. . Accessed 5 Oct 2020

Stuart-Macadam P, Kent S (1992) Diet, Demography and disease: changing patterns on anemia. Transaction Publishers, New York

Suckling G, Thurley DC (1984) Developmental defects of enamel: factors influencing their macroscopic appearance. In: Fearnhead FW, Suga S (eds) Tooth Enamel IV. Elsevier, Amsterdam, pp $357-362$

Temple DH, Goodman AH (2014) Bioarcheology has a "health" problem: conceptualizing "stress" and "health" in bioarcheological research. Am J Phys Anthropol 155:186-191. https://doi.org/10. 1002/ajpa.22602

Todd TW (1921) Age changes in the pubic bone. Am J Phys Anthropol 4:1-70. https://doi.org/10.1002/ajpa.1330040102

Towle I, Irish JD (2020) Recording and interpreting enamel hypoplasia in samples from archaeological and palaeoanthropological contexts. J Archaeol Sci 114:105077. https://doi.org/10.1016/j.jas. 2020.105077

Ubelaker DH (1989) Human skeletal remains: excavation, analysis, interpretation, 2nd edn. Taraxacum, Washington DC

Van de Poel E, Hosseinpoor AR, Speybroeck N, Van Ourti T, Vega J (2008) Socioeconomic inequality in malnutrition in developing countries. Bull World Health Organ 86:241-320

Various authors (1992) La civiltà picena nelle Marche: studi in onore di Giovanni Annibaldi: Ancona, 10-13 luglio 1988. Maroni Editore, Ripatransone

Vercellotti G, Stout SD, Boano R, Sciulli PW (2011) Intrapopulation variation in stature and body proportions: social status and sex differences in an Italian medieval population (Trino Vercellese, VC). Am J Phys Anthropol 145:203-214. https://doi.org/10. 1002/ajpa.21486

Walker P, Cook D (1998) Brief communication: gender and sex: Vive la difference. Am J Phys Anthropol 106:255-259

Walker PL (2005) Greater sciatic notch morphology: sex, age, and population differences. Am JPhys Anthropol 127:385-391. https:// doi.org/10.1002/ajpa.10422

Walker PL, Bathurst RR, Richman R, Gjerdrum T, Andrushko VA (2009) The causes of porotic hyperostosis and cribra orbitalia: a 
reappraisal of the iron-deficiency-anemia hypothesis. Am J Phys Anthropol 139:109-125. https://doi.org/10.1002/ajpa.21031

Weiss NM, Vercellotti G, Boano R, Girotti M, Stout SD (2019) Body size and social status in medieval Alba (Cuneo), Italy. Am J Phys Anthropol 168:595-605. https://doi.org/10.1002/ajpa.23776

WHO (1948) Preamble to the Constitution of WHO as adopted by the International Health Conference, New York, 19 June - 22 July 1946; signed on 22 July 1946 by the representatives of 61 States (Official Records of WHO, no. 2, p. 100) and entered into force on 7 April 1948

Wood JW, Milner GR, Harpending HC, Weiss KM (1992) The osteological paradox: problems of inferring prehistoric health from skeletal samples [and Comments and Reply]. Curr Anthropol 33:343-370. https://doi.org/10.1086/204084
Zoëga G, Murphy KA (2016) Life on the edge of the Arctic: the bioarchaeology of the Keldudalur Cemetery in Skagafjörður Iceland. Int J Osteoarchaeol 26(4):574-584. https://doi.org/10.1002/oa. 2446

Zuckerman MK, Crandall J (2019) Reconsidering sex and gender in relation to health and disease in bioarchaeology. J Anthropol Archaeol 54:161-171. https://doi.org/10.1016/j.jaa.2019.04.001

Publisher's note Springer Nature remains neutral with regard to jurisdictional claims in published maps and institutional affiliations. 